\title{
Single photon ionization of van der Waals clusters with a soft x-ray laser: $\left(\mathrm{CO}_{2}\right)_{n}$ and $\left(\mathrm{CO}_{2}\right)_{n}\left(\mathrm{H}_{2} \mathrm{O}\right)_{m}$
}

\author{
S. Heinbuch \\ Department of Electrical and Computer Engineering, Colorado State University, Fort Collins, \\ Colorado 80523 and NSF ERC for Extreme Ultraviolet Science and Technology, Colarado State University, \\ Fort Collins, Colorado 80523 \\ F. Dong \\ Department of Chemistry, Colorado State University, Fort Collins, Colorado 80523 and NSF ERC \\ for Extreme Ultraviolet Science and Technology, Colarado State University, Fort Collins, Colorado 80523

\section{J. J. Rocca} \\ Department of Electrical and Computer Engineering, Colorado State University, Fort Collins, \\ Colorado 80523 and NSF ERC for Extreme Ultraviolet Science and Technology, Colarado State University, \\ Fort Collins, Colorado 80523
}

\section{E. R. Bernstein ${ }^{\text {a) }}$}

Department of Chemistry, Colorado State University, Fort Collins, Colorado 80523 and NSF ERC for Extreme Ultraviolet Science and Technology, Colarado State University, Fort Collins, Colorado 80523

(Received 23 June 2006; accepted 11 August 2006; published online 20 October 2006)

Pure neutral $\left(\mathrm{CO}_{2}\right)_{n}$ clusters and mixed $\left(\mathrm{CO}_{2}\right)_{n}\left(\mathrm{H}_{2} \mathrm{O}\right)_{m}$ clusters are investigated employing time of flight mass spectroscopy and single photon ionization at $26.5 \mathrm{eV}$. The distribution of pure $\left(\mathrm{CO}_{2}\right)_{n}$ clusters decreases roughly exponentially with increasing cluster size. During the ionization process, neutral clusters suffer little fragmentation because almost all excess cluster energy above the vertical ionization energy is taken away by the photoelectron and only a small part of the photon energy is deposited into the $\left(\mathrm{CO}_{2}\right)_{n}$ cluster. Metastable dissociation rate constants of $\left(\mathrm{CO}_{2}\right)_{n}^{+}$are measured in the range of $(0.2-1.5) \times 10^{4} \mathrm{~s}^{-1}$ for cluster sizes of $5 \leqslant n \leqslant 16$. Mixed $\mathrm{CO}_{2}-\mathrm{H}_{2} \mathrm{O}$ clusters are studied under different generation conditions $\left(5 \%\right.$ and $20 \% \mathrm{CO}_{2}$ partial pressures and high and low expansion pressures). At high $\mathrm{CO}_{2}$ concentration, predominant signals in the mass spectrum are the $\left(\mathrm{CO}_{2}\right)_{n}^{+}$cluster ions. The unprotonated cluster ion series $\left(\mathrm{CO}_{2}\right)_{n} \mathrm{H}_{2} \mathrm{O}^{+}$and $\left(\mathrm{CO}_{2}\right)_{n}\left(\mathrm{H}_{2} \mathrm{O}\right)_{2}^{+}$are also observed under these conditions. At low $\mathrm{CO}_{2}$ concentration, protonated cluster ions $\left(\mathrm{H}_{2} \mathrm{O}\right)_{n} \mathrm{H}^{+}$are the dominant signals, and the protonated $\mathrm{CO}_{2}\left(\mathrm{H}_{2} \mathrm{O}\right)_{n} \mathrm{H}^{+}$and unprotonated $\left(\mathrm{H}_{2} \mathrm{O}\right)_{n}^{+}$and $\left(\mathrm{CO}_{2}\right)$ $\times\left(\mathrm{H}_{2} \mathrm{O}\right)_{n}^{+}$cluster ion series are also observed. The mechanisms and dynamics of the formation of these neutral and ionic clusters are discussed. () 2006 American Institute of Physics. [DOI: $10.1063 / 1.2348877$ ]

\section{INTRODUCTION}

Carbon dioxide is the major gas phase pollutant responsible for the "greenhouse effect" of the atmosphere. ${ }^{1}$ Many experiments employing supersonic expansion coupled with mass spectroscopic detection have been conducted in order to study monomeric and clustered $\mathrm{CO}_{2}$ structure and behavior. $^{2-21}$ Spectroscopic and photochemical properties of $\left(\mathrm{CO}_{2}\right)_{n}$ should be related to cluster structure.

Small $\mathrm{CO}_{2}$ clusters have been studied by Linn and $\mathrm{Ng}^{6(\mathrm{a})}$ employing a discharge lamp source in the wavelength range of $65-69 \mathrm{~nm}$ to measure the photoionization efficiency curves for $\left(\mathrm{CO}_{2}\right)_{2},\left(\mathrm{CO}_{2}\right)_{3}$, and $\left(\mathrm{CO}_{2}\right)_{4}$. They obtained ionization energy (IE) values of $13.32 \pm 0.02,13.24 \pm 0.02$, and $13.18 \pm 0.01 \mathrm{eV}$, respectively, for these cluster species. The $\mathrm{IE}$ of the $\mathrm{CO}_{2}$ monomer had previously been determined at $13.77 \pm 0.01 \mathrm{eV}^{6(\mathrm{~b})}$ The structure of $\left(\mathrm{CO}_{2}\right)_{n}^{+}$clusters has been explored through electron diffraction experiments ${ }^{7-9}$ and molecular dynamics simulations. ${ }^{10}$ Clusters of size $n \geqslant 100$ ap-

a)Electronic mail: erb@lamar.colostate.edu parently have a cubic structure. ${ }^{7}$ Clusters with $n \leqslant 100$ undergo a cubic (large) to octahedral (small) structure change in the range $n \sim 20-55$. IR and Raman spectroscopies have demonstrated crystalline structures in even larger clusters. ${ }^{11-13}$ Scanning electron microscope experiments have shown octahedral forms for $\mathrm{CO}_{2}$ crystals of $\sim 0.1 \mu \mathrm{m}$ diameter. ${ }^{14}$

While few reports of photoionization studies of $\mathrm{CO}_{2}$ clusters are available, many experiments employing electron impact ionization of $\left(\mathrm{CO}_{2}\right)_{n}$ clusters have appeared. This is probably due to the high ionization energy for $\mathrm{CO}_{2}$. Size dependent fragmentation electron impact experiments have recently been reported for $\left(\mathrm{CO}_{2}\right)_{n}$ clusters. Three series of fragment ions are observed: $\left(\mathrm{CO}_{2}\right)_{n} \mathrm{O}^{+},\left(\mathrm{CO}_{2}\right)_{n} \mathrm{CO}^{+}$, and $\left(\mathrm{CO}_{2}\right)_{n} \mathrm{O}_{2}^{+}$. The fragment (daughter) cluster ions are formed from the loss of $\mathrm{CO}$ and $\mathrm{O}$ from parent ions. The ions corresponding to $\left(\mathrm{CO}_{2}\right)_{n} \mathrm{O}_{2}^{+}$daughters may arise from $\left(\mathrm{CO}_{2}\right)_{n+1} \mathrm{O}^{+}$losing one $\mathrm{CO}$ molecule. ${ }^{16}$ Relative intensity anomalies are also observed at $n=4,5$ and $n=15,16$ at multiple stagnation pressures. The increased cluster ion intensity 


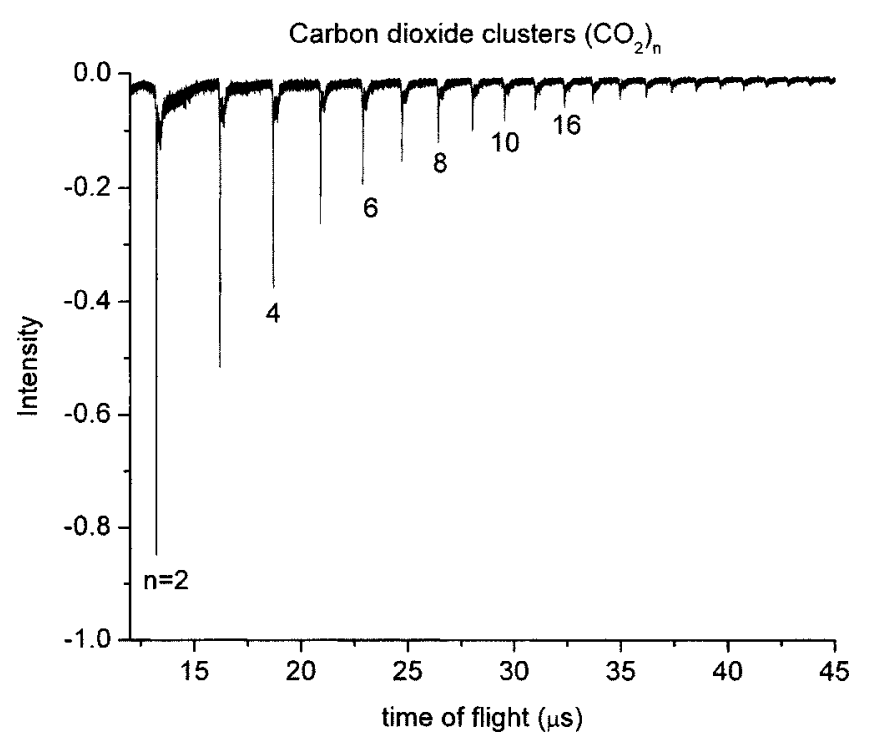

FIG. 1. A linear TOF mass spectrum of $\mathrm{CO}_{2}$ clusters ionized by a $26.5 \mathrm{eV}$ soft x-ray laser. The $\mathrm{CO}_{2}$ clusters are generated by expansion of $20 \%$ $\mathrm{CO}_{2} / \mathrm{Ar}$ mixed gas at $80 \mathrm{psi}$.

at $n=4,5$ can be attributed to a stable symmetrical structure for the $\left(\mathrm{CO}_{2}\right)_{n}^{+}$ion. ${ }^{17}$ The intensity anomaly at cluster sizes $n=15,16$ is attributed to a "magic number," the first assigned to a van der Waals cluster. Unfortunately, as in most electron impact cluster studies, fragmentation effects from larger clusters tend to blur the true relative intensities of the neutral cluster size distribution. ${ }^{16}$ With this technique, one does not observe the true neutral cluster distribution.

A few studies have been conducted involving mixed $\mathrm{CO}_{2} / \mathrm{H}_{2} \mathrm{O}$ clusters and these agree that the $\mathrm{CO}_{2} / \mathrm{H}_{2} \mathrm{O}$ bond is not a hydrogen bond. The neutral $\mathrm{CO}_{2} \mathrm{H}_{2} \mathrm{O}$ cluster has a T-shaped structure in which the hydrogens point away from the $\mathrm{CO}_{2}$ molecule. These latter results are based on IR spectroscopy $^{22}$ and $a b$ initio calculations. ${ }^{22,23}$ Theoretical studies of larger cluster ions suggest that the $\mathrm{CO}_{2}-\mathrm{H}_{2} \mathrm{O}$ bond is no longer a van der Waals bond but a weak hydrogen bond that is susceptible to cleavage. ${ }^{24}$ These details will be reexamined in the Discussion section on the mixed cluster ion $\left(\mathrm{CO}_{2}\right)_{n}\left(\mathrm{H}_{2} \mathrm{O}\right)_{m}$ series.

In the present study, carbon dioxide and mixed carbon dioxide-water clusters are accessed by single photon ionization with a $26.5 \mathrm{eV}(46.9 \mathrm{~nm})$ soft x-ray laser. The distributions of neutral $\left(\mathrm{CO}_{2}\right)_{n}$ and $\left(\mathrm{CO}_{2}\right)_{n}\left(\mathrm{H}_{2} \mathrm{O}\right)_{m}$ clusters are detected and metastable dissociation rate constants for $\left(\mathrm{CO}_{2}\right)_{n}^{+}$ cluster ions are measured in the range of $5 \leqslant n \leqslant 16$ and for $\left(\mathrm{CO}_{2}\right)_{n} \mathrm{H}_{2} \mathrm{O}$ in the range of $5 \leqslant n \leqslant 9$. $\left(\mathrm{CO}_{2}\right)_{n}^{+}$cluster ions are the dominant products in the photoionization of neutral $\left(\mathrm{CO}_{2}\right)_{n}$ clusters using a single photon of $26.5 \mathrm{eV}$ energy for ionization. Compared with electron impact techniques, $\left(\mathrm{CO}_{2}\right)_{n}$ clusters suffer only a small dissociation by this present single photon ionization and a nearly accurate neutral cluster distribution is observed by time of flight mass spectroscopy (TOFMS). The neutral cluster distribution $\left(\mathrm{CO}_{2}\right)_{n}$, as observed through $\left(\mathrm{CO}_{2}\right)_{n}^{+}$ions, shows no sign of anomalous relative intensity peaks that could be termed magic numbers associated with van der Waals clusters. For the neutral $\mathrm{CO}_{2}-\mathrm{H}_{2} \mathrm{O}$ cluster series, both $\left(\mathrm{CO}_{2}\right)_{n}\left(\mathrm{H}_{2} \mathrm{O}\right)^{+}$and
$\left(\mathrm{CO}_{2}\right)\left(\mathrm{H}_{2} \mathrm{O}\right)_{n} \mathrm{H}^{+}$cluster ions are observed under different experimental conditions. Also observed is the unprotonated water cluster ion series that is not observed for pure neutral water clusters ionized by $26.5 \mathrm{eV}$ photons. ${ }^{25}$ The mechanism for mixed cluster formation is discussed in detail in this report.

\section{EXPERIMENTAL PROCEDURES}

The experimental apparatus and soft x-ray laser have been described in previous publications from this laboratory, ${ }^{25,26}$ and therefore only a general outline of the experimental scheme will be presented in this report. A tabletop soft $\mathrm{x}$-ray laser ( $26.5 \mathrm{eV}$ photons) is used as the single photon ionization source. ${ }^{27}$ The laser emits pulses of ca. $1 \mathrm{~ns}$ duration with an energy of ca. $10 \mu \mathrm{J} /$ pulse at a repetition rate of $12 \mathrm{~Hz}$. A time of flight (linear/reflectron) mass spectrometer is used as a mass analyzer. A pair of mirrors placed in $Z$-fold configuration just before the ionization region of the TOFMS provides alignment capability and focus for the laser beam with respect to the molecular beam at the ionization source. The $Z$-fold transmissivity is about $10 \%$ and thus the ionization point in the TOFMS receives about $1 \mu \mathrm{J} /$ pulse laser energy. Since the $26.5 \mathrm{eV}$ photons from the soft $\mathrm{x}$-ray laser are able to ionize the He carrier gas employed in the supersonic expansion discussed below, the microchannel plate mass detector voltage is gated to reduce the gain of the plates when $\mathrm{He}^{+}$ions arrive at the microchannel plate (MCP) in order to prevent detector circuit overload and saturation.

Pure neutral $\left(\mathrm{CO}_{2}\right)_{n}$ clusters are generated in a supersonic expansion of $20 \% \mathrm{CO}_{2} / \mathrm{He}$ or $\mathrm{Ar}$ mixed gases from a pulsed nozzle (200 $\mu \mathrm{m}$ diameter opening) at 80 psi backing pressure. A mixed $\mathrm{CO}_{2}-\mathrm{H}_{2} \mathrm{O}$ gas is obtained by flowing $5 \%$ or $20 \% \mathrm{CO}_{2} / \mathrm{He}$ at pressure of 30 or 80 psi through a reservoir containing liquid water at room temperature. Mixed $\mathrm{CO}_{2} / \mathrm{H}_{2} \mathrm{O}$ clusters are generated in the molecular beam by expanding the gas mixture into a vacuum chamber. $\mathrm{CO}_{2}$ and gases used in these experiments are $99.9 \%$ pure from General Air. The molecular beam is collimated by a skimmer with a $2.0 \mathrm{~mm}$ diameter hole at its apex, located approximately $2 \mathrm{~cm}$ downstream from the nozzle. Chamber pressure in the field-free and detector regions of the TOFMS is $2 \times 10^{-6}$ Torr during the experiment. Experiments are conducted to ensure that collision induced dissociation of cluster ions is negligible. The pressure in the beam at the ionization region (ca. $10^{-5}$ Torr) is too low to cause collision induced ionization of $\left(\mathrm{CO}_{2}\right)_{n}$.

\section{RESULTS}

\section{A. Distribution of $\mathrm{CO}_{2}$ clusters ionized by a $26.5 \mathrm{eV}$ soft x-ray laser}

Figure 1 displays a linear TOF mass spectrum of $\mathrm{CO}_{2}$ clusters photoionized by a single photon of $26.5 \mathrm{eV}$ energy. The spectrum reveals the size distribution of the clusters as they are generated in the ionization/extraction region of the TOFMS on a time scale of less than $1 \mu$ s after ionization. The distribution of $\left(\mathrm{CO}_{2}\right)_{n}^{+}(2 \leqslant n \leqslant 20)$ clusters that dominate the spectrum decreases approximately exponentially as a function of increasing cluster size $n$. If the intensity scale is 


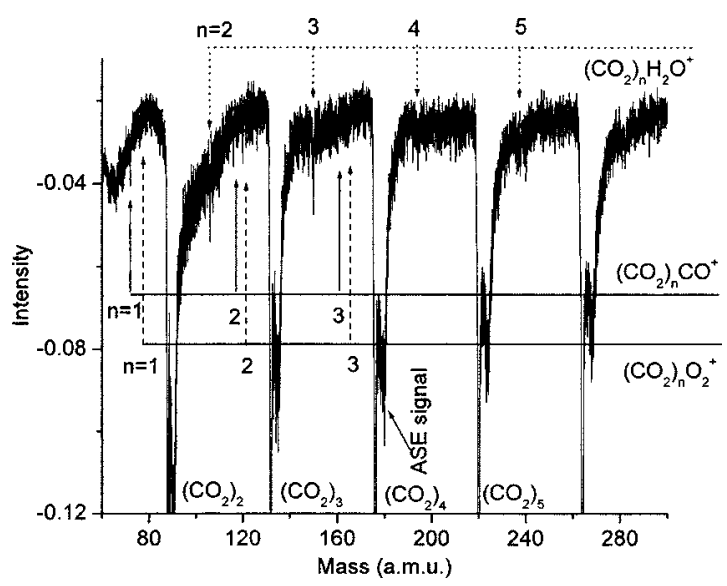

FIG. 2. An expansion of the scale in Fig. 1 showing the weak intensity dissociated cluster ion series $\left(\mathrm{CO}_{2}\right)_{n} \mathrm{O}_{2}^{+}$and $\left(\mathrm{CO}_{2}\right)_{n} \mathrm{CO}^{+}$. ASE is the amplified spontaneous emission from the creation of the laser plasma. For more information see Ref. 27 and the references therein.

expanded, as shown in Fig. 2, one can observe other cluster series in the mass spectrum: in particular, the series $\left(\mathrm{CO}_{2}\right)_{n} \mathrm{O}_{2}^{+}$and $\left(\mathrm{CO}_{2}\right)_{n} \mathrm{CO}^{+}$are fragment features. They arise within the time frame of the ca. 1 ns laser pulse, as the features are sharp ( $\sim 10 \mathrm{~ns}$ for an Ar expansion) and do not tail off to the high mass side of the spectrum, as would be expected for slow fragmentation $\left(1 \mu \mathrm{s}>\tau_{\text {frag }}>10 \mathrm{~ns}\right)$ in the extraction region. One also notes a series of mixed watercarbon dioxide clusters $\left(\mathrm{CO}_{2}\right)_{n} \mathrm{H}_{2} \mathrm{O}^{+}$, due to residual water in the expansion gases, nozzle, or vacuum system. The three pure $\mathrm{CO}_{2}$ cluster ion series arise as follows:

$$
\begin{aligned}
&\left(\mathrm{CO}_{2}\right)_{n}+h \nu \rightarrow\left(\mathrm{CO}_{2}\right)_{n}^{+}+e^{-} \\
& \rightarrow\left(\mathrm{CO}_{2}\right)_{n-1} \mathrm{CO}^{+}+\mathrm{O}+e^{-} \\
& \rightarrow\left(\mathrm{CO}_{2}\right)_{n-1} \mathrm{O}^{+}+\mathrm{CO}+e^{-} \\
&\left(\mathrm{CO}_{2}\right)_{n-1} \mathrm{O}^{+}+\mathrm{CO}+\mathrm{O}+e^{-} \\
& \rightarrow\left(\mathrm{CO}_{2}\right)_{n-2} \mathrm{O}_{2}^{+}+\mathrm{CO}+\mathrm{O}+e^{-} .
\end{aligned}
$$

To be certain that the $\left(\mathrm{CO}_{2}\right)_{n-2} \mathrm{O}_{2}^{+}$cluster ion series does not originate from residual $\mathrm{O}_{2}$ in the system, a test is conducted in which $10 \% \mathrm{O}_{2} / \mathrm{He}$ is employed as the backing gas and the signal intensity of $\left(\mathrm{CO}_{2}\right)_{n-2} \mathrm{O}_{2}^{+}$cluster ions is monitored. No enhancement of the signals in these mass channels is observed, indicating that reaction (3) is the actual mechanism for the appearance of the $\left(\mathrm{CO}_{2}\right)_{n-2} \mathrm{O}_{2}^{+}$series of cluster ions. If these results are compared to those for electron impact ionization, ${ }^{16}$ as expected, one finds significantly less cluster fragmentation generated by $26.5 \mathrm{eV}$ photoionization.

\section{B. Mixed carbon dioxide-water clusters}

Mixed $\mathrm{CO}_{2}-\mathrm{H}_{2} \mathrm{O}$ clusters are generated by expanding a mixed gas of $\mathrm{CO}_{2} / \mathrm{He}$ and water vapor into the vacuum chamber at room temperature. Mixed $\mathrm{CO}_{2}-\mathrm{H}_{2} \mathrm{O}$ clusters are generated under two experimental conditions: (1) $20 \%$ $\mathrm{CO}_{2} / \mathrm{He}$ mixed with water vapor at $80 \mathrm{psi}$ backing pressure and (2) $5 \% \mathrm{CO}_{2} / \mathrm{He}$ mixed with water vapor at $30 \mathrm{psi}$ backing pressure. Figure 3 shows a mass spectrum of mixed

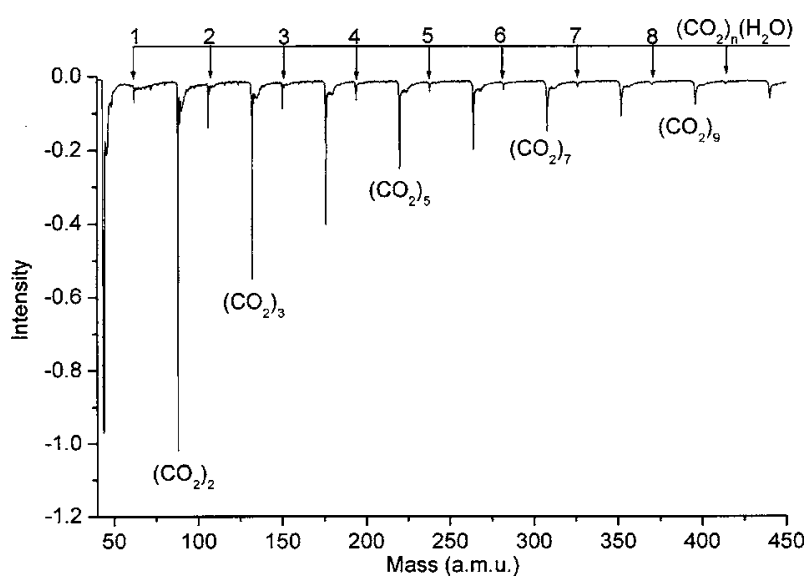

FIG. 3. A high resolution spectrum of mixed $\mathrm{CO}_{2}-\mathrm{H}_{2} \mathrm{O}$ clusters that are generated by expansion of mixed gas $20 \% \mathrm{CO}_{2} /$ water vapor/He at $80 \mathrm{psi}$ backing pressure. Cluster ions $\left(\mathrm{CO}_{2}\right)_{n}^{+}$dominate mass spectrum. The signal intensity of cluster ions $\left(\mathrm{CO}_{2}\right)_{n}\left(\mathrm{H}_{2} \mathrm{O}\right)^{+}$is about $10 \%$ of the intensity of the cluster ions $\left(\mathrm{CO}_{2}\right)_{n}^{+}$, for values of $n<10$.

$\mathrm{CO}_{2}-\mathrm{H}_{2} \mathrm{O}$ clusters formed under condition 1 . At this high pressure, high $\mathrm{CO}_{2}$ content condition, $\left(\mathrm{CO}_{2}\right)_{n}^{+}$cluster ions dominate the spectrum, and pure water clusters are not observed. The same exponential decrease in the cluster ion distribution is noticed relative to the distribution without water in the beam. Again if the scale of Fig. 3 is expanded, as in Fig. 4, new pure and mixed cluster ion series are observed. In addition to the pure cluster series $\left(\mathrm{CO}_{2}\right)_{n}^{+}$and $\left(\mathrm{CO}_{2}\right)_{n} \mathrm{CO}^{+}$, the two mixed cluster series $\left(\mathrm{CO}_{2}\right)_{n}\left(\mathrm{H}_{2} \mathrm{O}\right)_{2}$ and $\left(\mathrm{CO}_{2}\right)_{n} \mathrm{H}_{2} \mathrm{O}$ can be observed: note that all of these clusters are unprotonated. The signal intensities for the cluster ions $\left(\mathrm{CO}_{2}\right)_{n} \mathrm{H}_{2} \mathrm{O}^{+}$ are approximately $10 \%$ of the intensities for the cluster ions $\left(\mathrm{CO}_{2}\right)_{n}^{+}$for $n=2-5$. Additionally, some small signals of $\left(\mathrm{CO}_{2}\right)_{2,3} \mathrm{H}_{2} \mathrm{OH}^{+}$cluster ions are observed. Figure 5 illustrates metastable dissociation for cluster ions $\left(\mathrm{CO}_{2}\right)_{n}^{+}$, and for the mixed cluster ions $\left(\mathrm{CO}_{2}\right)_{n} \mathrm{H}_{2} \mathrm{O}^{+}$for $n=5-8$ at condition 1 . The spectrum of Fig. 5 is observed with the TOFMS operating in reflectron mode and indicates the population of cluster ions as found in the first field-free region of the TOFMS within the time window of $1-100 \mu \mathrm{s}$. The peaks labeled $\left(\mathrm{CO}_{2}\right)_{n+1}$ are the parent ion clusters of the daughter ion peaks labeled $\mathrm{D}_{n}$. The daughter ions are generated by loss of one $\mathrm{CO}_{2}$ molecule from the parent ion. Similarly, the peaks labeled $\left(\mathrm{CO}_{2}\right)_{n+1} \mathrm{H}_{2} \mathrm{O}^{+}$are the parent cluster ions of the daughter peaks labeled $\mathrm{B}_{n}$ produced by loss of one $\mathrm{CO}_{2}$ molecule from the parent ion.

If the concentration of $\mathrm{CO}_{2}$ in the backing gas and the backing pressure are reduced to that of condition 2 (low concentration and pressure), the dominant signal in the mass spectrum changes from $\left(\mathrm{CO}_{2}\right)_{n}^{+}$to $\left(\mathrm{H}_{2} \mathrm{O}\right)_{n} \mathrm{H}^{+}(n=3-22)$ as illustrated in Fig. 6. The $\left(\mathrm{CO}_{2}\right)_{n}^{+}$signal is less intense but still observable. Expanding the scale, as shown in Fig. 7, displays three more cluster ion series. The protonated mixed cluster ions $\left(\mathrm{CO}_{2}\right)\left(\mathrm{H}_{2} \mathrm{O}\right)_{n} \mathrm{H}^{+}$appear in the mass spectrum and are generated from the mixed neutral cluster $\left(\mathrm{CO}_{2}\right)\left(\mathrm{H}_{2} \mathrm{O}\right)_{n+1}$ by a proton transfer reaction following ionization:

$$
\begin{aligned}
\left(\mathrm{CO}_{2}\right)\left(\mathrm{H}_{2} \mathrm{O}\right)_{n+1}+h \nu & \rightarrow\left\{\left(\mathrm{CO}_{2}\right)\left(\mathrm{H}_{2} \mathrm{O}\right)_{n+1}^{+}\right\}^{*}+e^{-} \\
& \rightarrow\left(\mathrm{CO}_{2}\right)\left(\mathrm{H}_{2} \mathrm{O}\right)_{n} \mathrm{H}^{+}+\mathrm{OH}+e^{-} .
\end{aligned}
$$

Unprotonated cluster ions $\left(\mathrm{CO}_{2}\right)\left(\mathrm{H}_{2} \mathrm{O}\right)_{n}^{+}$and $\left(\mathrm{H}_{2} \mathrm{O}\right)_{n}^{+}$appear 


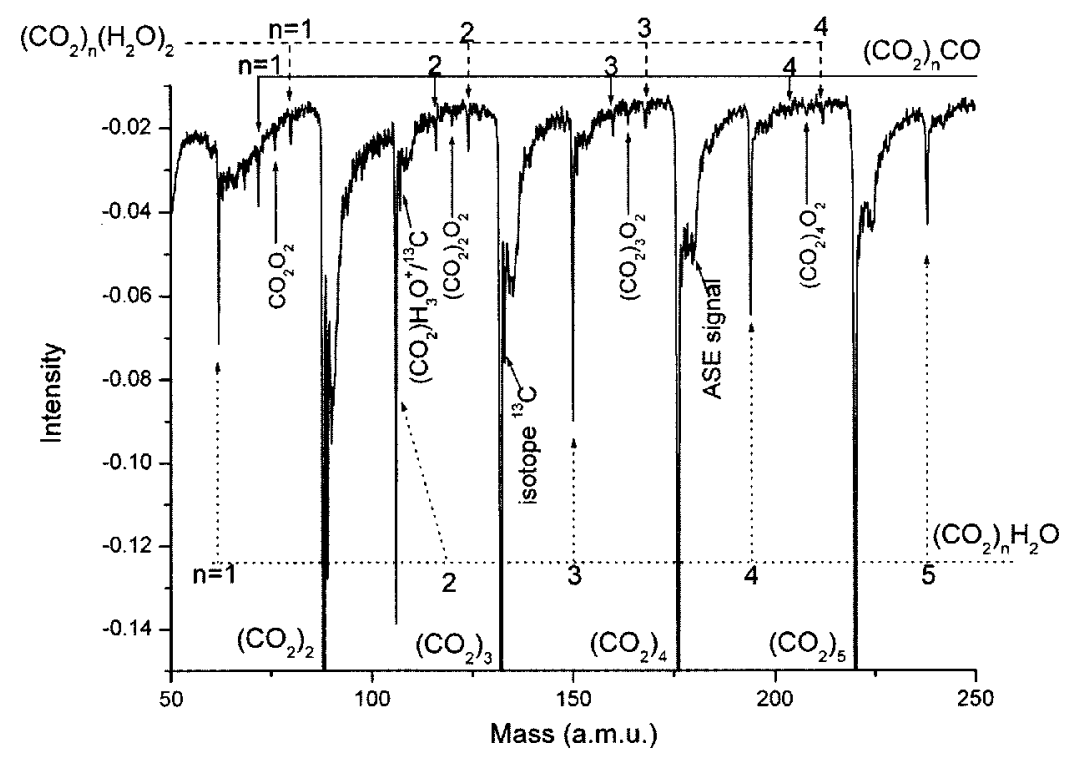

FIG. 4. An expanded scale view of Fig. 3 revealing the cluster ion series $\left(\mathrm{CO}_{2}\right)_{n}\left(\mathrm{H}_{2} \mathrm{O}\right)^{+}$and $\left(\mathrm{CO}_{2}\right)_{n}\left(\mathrm{H}_{2} \mathrm{O}\right)_{2}^{+}$. ASE is the amplified spontaneous emission from the creation of the laser plasma. For more information see Ref. 27 and the references therein.

in the mass spectrum as well and may be generated by the reactions

$$
\begin{aligned}
\left(\mathrm{CO}_{2}\right)_{m}\left(\mathrm{H}_{2} \mathrm{O}\right)_{n+1}+h \nu & \rightarrow\left\{\left(\mathrm{CO}_{2}\right)_{m}\left(\mathrm{H}_{2} \mathrm{O}\right)_{n+1}^{+}\right\}^{*}+e^{-} \\
& \rightarrow\left(\mathrm{CO}_{2}\right)\left(\mathrm{H}_{2} \mathrm{O}\right)_{n}^{+}+(m-1) \mathrm{CO}_{2}+e^{-} \\
& \rightarrow\left(\mathrm{H}_{2} \mathrm{O}\right)_{n}^{+}+m \mathrm{CO}_{2}+e^{-}
\end{aligned}
$$

Mixed cluster ions containing more than one $\mathrm{CO}_{2}$ molecule are not observed except for $\left(\mathrm{CO}_{2}\right)_{2}\left(\mathrm{H}_{2} \mathrm{O}\right)_{n}^{+} n=1,2$. The generation of mixed $\mathrm{CO}_{2}-\mathrm{H}_{2} \mathrm{O}$ cluster ions will be discussed in more detail in the next section.

Figure 8 presents metastable dissociation of cluster $\left(\mathrm{H}_{2} \mathrm{O}\right)_{n} \mathrm{H}+^{+}$for $n=8-16$ at condition 2 . The peaks labeled $\mathrm{A}_{n}$ are the parent ion clusters of the daughter peaks labeled $D_{n-1}$ produced by the loss of one $\mathrm{H}_{2} \mathrm{O}$ molecule from the parent ion $\mathrm{A}_{n}$. The relative signal intensities of the parent and daughter ions switch dominance at $n \sim 14$.

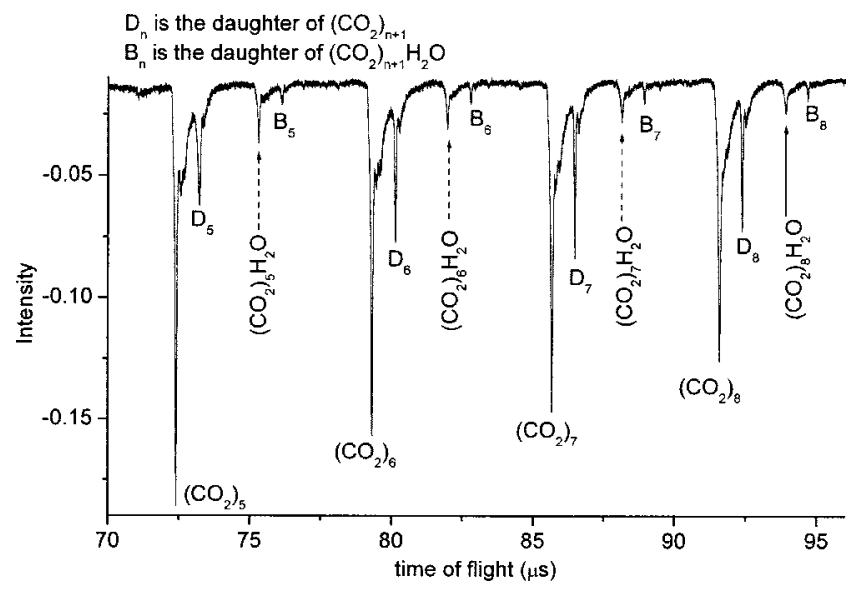

FIG. 5. A high resolution reflectron TOF mass spectrum of $\left(\mathrm{CO}_{2}\right)_{n}$ clusters Metastable dissociation of $\left(\mathrm{CO}_{2}\right)_{n}^{+}$and $\left(\mathrm{CO}_{2}\right)_{n} \mathrm{HO}^{+}$cluster ions in the fieldfree region is observed. $\mathrm{B}_{n}\left(\mathrm{CO}_{2}\right)_{n} \mathrm{H}_{2} \mathrm{O}$ is the daughter peak of $\left(\mathrm{CO}_{2}\right)_{n+1} \mathrm{H}_{2} \mathrm{O}$ and $\mathrm{D}_{n}\left(\mathrm{CO}_{2}\right)_{n}$ is the daughter peak of $\left(\mathrm{CO}_{2}\right)_{n+1}$. See text for a discussion of the metastable fragmentation.

\section{Metastable dissociation rate constants for $\left(\mathrm{CO}_{2}\right)_{n}^{+}$ and $\left(\mathrm{CO}_{2}\right)_{n} \mathrm{H}_{2} \mathrm{O}^{+}$cluster ions}

Figure 5 presents a reflectron TOF mass spectrum indicating the population distribution of cluster ions formed in the first field-free region of the TOFMS. Daughter ions are produced from their parent ions by metastable dissociation reactions in the drift tube. Based on our previous studies of weakly bound cluster ions with both van der Waals and hydrogen bonding structures [e.g., $\left(\mathrm{H}_{2} \mathrm{O}\right)_{n},\left(\mathrm{CH}_{3} \mathrm{OH}\right)_{n},\left(\mathrm{NH}_{3}\right)_{n}$, $\left.\left(\mathrm{SO}_{2}\right)_{n}\right]$, we can assume that only one $\mathrm{CO}_{2}$ molecule is lost from each $\left(\mathrm{CO}_{2}\right)_{n}^{+}$and $\left(\mathrm{CO}_{2}\right)_{n} \mathrm{H}_{2} \mathrm{O}^{+}$parent cluster ion to generate the daughter ions. The unimolecular metastable dissociation rate constants for $\left(\mathrm{CO}_{2}\right)_{n}^{+}$and $\left(\mathrm{CO}_{2}\right)_{n} \mathrm{H}_{2} \mathrm{O}^{+}$cluster ion dissociation can be calculated as

$$
k=-\left(\frac{1}{t}\right) \ln \left[1-I_{D} /\left(I_{D}+I_{P}\right)\right],
$$

in which $I_{D}$ and $I_{P}$ are the intensities of the dissociated daughter ion and the undissociated parent ions, respectively. $t$ is time of flight of the parent ion in the first field-free region

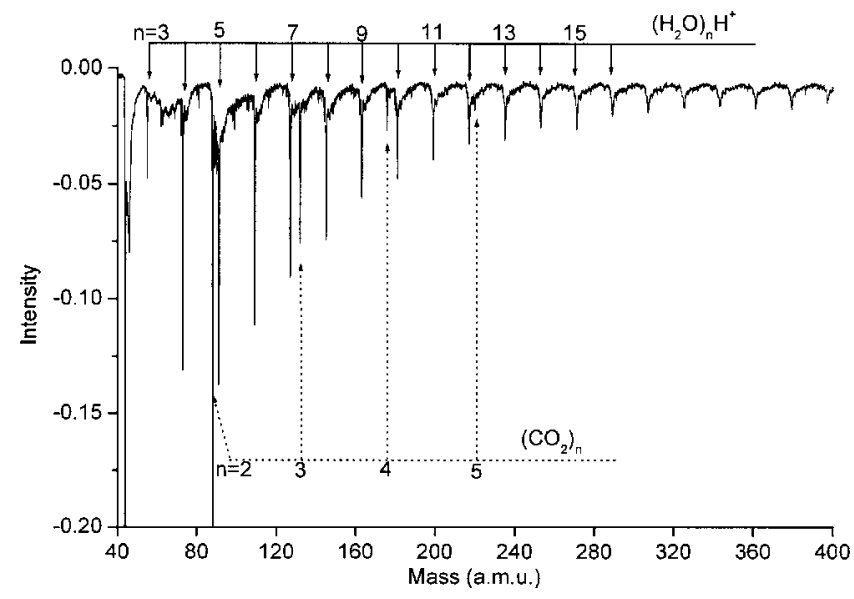

FIG. 6. A high resolution spectrum of mixed $\mathrm{CO}_{2}-\mathrm{H}_{2} \mathrm{O}$ clusters that are generated by expansion of mixed gas $5 \% \quad \mathrm{CO}_{2} /$ water vapor/He at $30 \mathrm{psi}$ backing pressure. Protonated water cluster ions $\left(\mathrm{H}_{2} \mathrm{O}\right)_{n} \mathrm{H}^{+}$dominate mass spectrum while $\left(\mathrm{CO}_{2}\right)_{n}^{+}$cluster ions are still observed. 


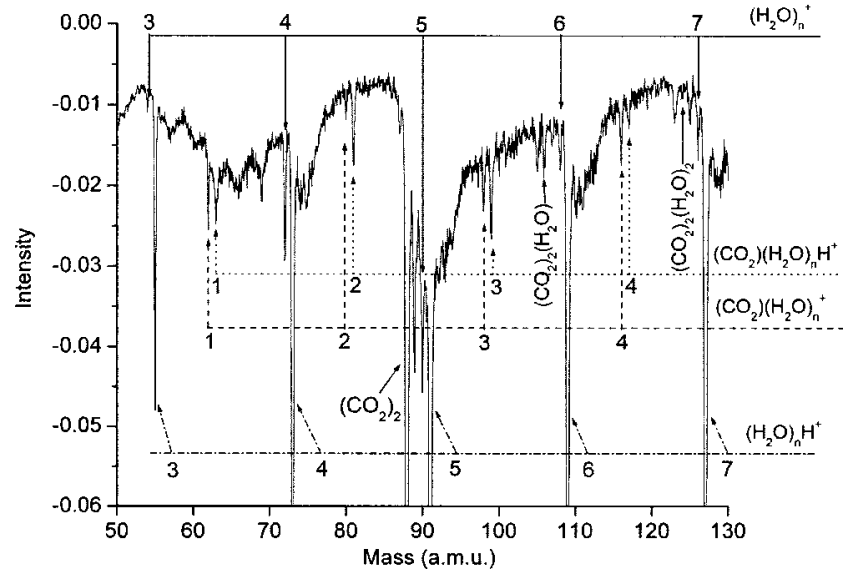

FIG. 7. An expanded scale view of Fig. 6 revealing the protonated cluster ion series $\left(\mathrm{CO}_{2}\right)\left(\mathrm{H}_{2} \mathrm{O}\right)_{n} \mathrm{H}^{+}$, and the unprotonated series $\left(\mathrm{CO}_{2}\right)\left(\mathrm{H}_{2} \mathrm{O}\right)_{n}^{+}$, $\left(\mathrm{CO}_{2}\right)_{2}\left(\mathrm{H}_{2} \mathrm{O}\right)_{n}^{+}$, and $\left(\mathrm{H}_{2} \mathrm{O}\right)_{n}^{+}$.

of the reflectron TOFMS. For the present apparatus this is about $60 \%$ of the total flight time for the reflectron mode TOFMS. Figure 9 shows that these rate constants, for cluster ions $5 \leqslant n \leqslant 12$, fall between $0.1 \times 10^{4}$ and $1.0 \times 10^{4} \mathrm{~s}^{-1}$. The $k$ values for $\left(\mathrm{CO}_{2}\right)_{n} \mathrm{H}_{2} \mathrm{O}^{+}$are similar to those for $\left(\mathrm{CO}_{2}\right)_{n}^{+}$for the same $n$ values. These values are also very similar to those found in our previous studies of van der Waals and hydrogen bonded clusters. ${ }^{25}$ We hypothesize that the $\left(\mathrm{CO}_{2}\right)_{n} \mathrm{H}_{2} \mathrm{O}^{+}$ daughter cluster ion series is formed through a process in which the parent ion loses one $\mathrm{CO}_{2}$ molecule, not water. This conclusion is drawn from an analysis of the flight time difference between the parent and its respective daughter ion in each series. For the $\left(\mathrm{CO}_{2}\right)_{n}^{+}$cluster ion series, the parent/ daughter flight time difference $\Delta\left(t_{p}-t_{D}\right)=6.11,5.49$, and $5.12 \mu \mathrm{s}$ for $n=6,7$, and 8, respectively. For the $\left(\mathrm{CO}_{2}\right)_{n} \mathrm{H}_{2} \mathrm{O}^{+}$ cluster ion series, $\Delta\left(t_{p}-t_{D}\right)=5.95,5.38$, and $4.99 \mu$ s for $m$ $=6,7$, and 8 , respectively. The similarity between these series timing differences implies that the $\left(\mathrm{CO}_{2}\right)_{n} \mathrm{H}_{2} \mathrm{O}^{+}$cluster ion series loses one $\mathrm{CO}_{2}$ unit in the drift tube. Moreover, the overall rate constant similarities for all these metastable dissociations strongly favor the conclusion that all these cluster

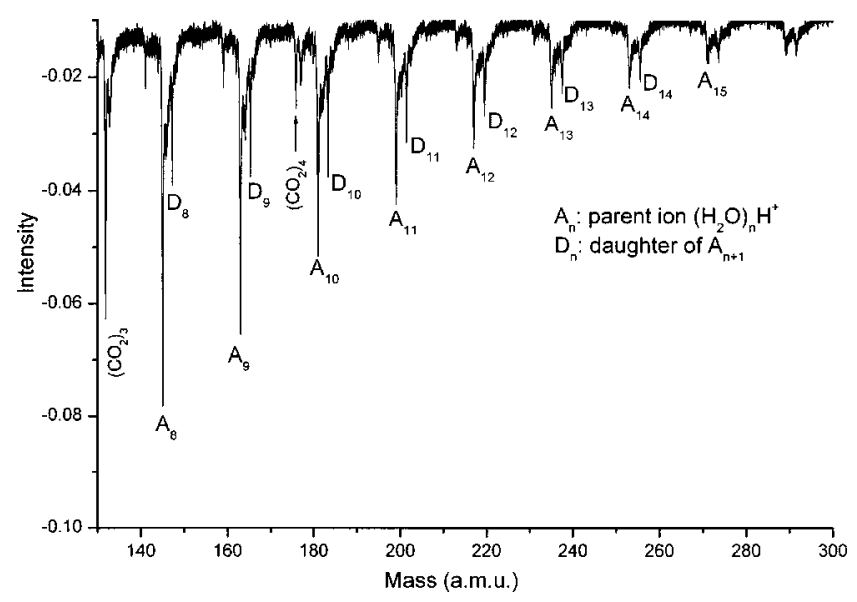

FIG. 8. A high resolution reflectron TOF mass spectrum of the $\mathrm{CO}_{2}-\mathrm{H}_{2} \mathrm{O}$ mixed cluster system for low pressure flow concentration $\mathrm{CO}_{2}$ conditions. Metastable dissociation of $\left(\mathrm{H}_{2} \mathrm{O}\right)_{n} \mathrm{H}^{+}$cluster ions in the field-free region is observed.

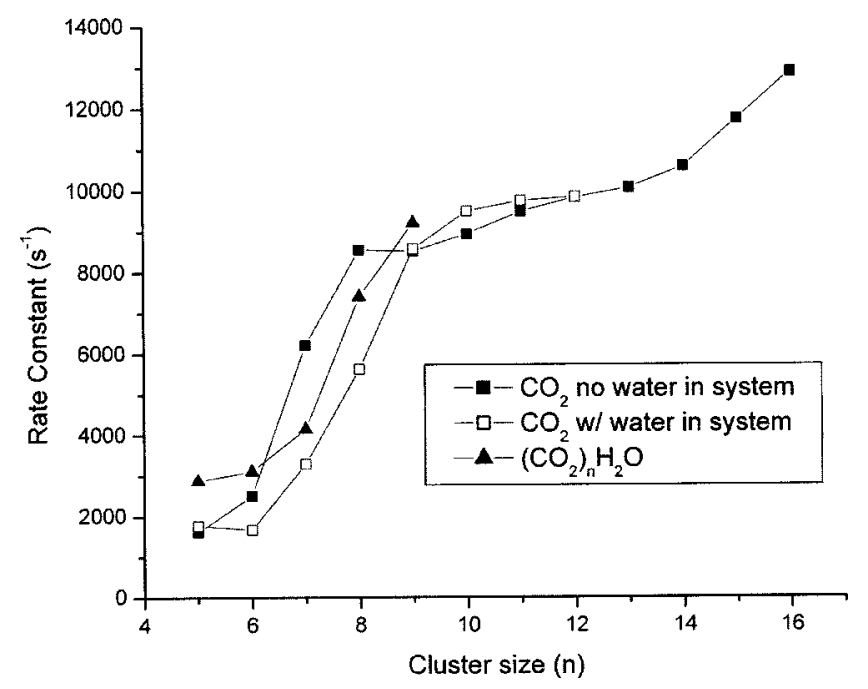

FIG. 9. A plot of metastable dissociation rate constants for $\left(\mathrm{CO}_{2}\right)_{n}^{+}$(with and without water experimentally added to the system), and $\left(\mathrm{CO}_{2}\right)_{n} \mathrm{H}_{2} \mathrm{O}^{+}$cluster ions as a function of the cluster size $n$.

ions lose the same number of components to metastable dissociation in the drift. The mass spectral peak shapes and widths for the TOF mass spectral features also imply that rapid dissociation following ionization within the ion extraction region of the TOFMS (10 ns $-1 \mu \mathrm{s})$ does not occur for any of these van der Waals and hydrogen bonded clusters. The results plotted in Fig. 9 are consistent with the the conclusion that $\mathrm{CO}_{2}$ cluster ions generated in the mixed system also come from neutral $\left(\mathrm{CO}_{2}\right)_{n}$ clusters and not the mixed clusters $\left(\mathrm{CO}_{2}\right)_{n}\left(\mathrm{H}_{2} \mathrm{O}\right)_{n}^{+}$.

\section{DISCUSSION}

\section{A. Distribution of $\left(\mathrm{CO}_{2}\right)_{n}$ clusters}

We have learned from both this study of $\mathrm{CO}_{2}$ clusters and previous studies of $\mathrm{H}_{2} \mathrm{O}, \mathrm{CH}_{3} \mathrm{OH}, \mathrm{NH}_{3}$, and $\mathrm{SO}_{2}$ clusters that $26.5 \mathrm{eV}$ photons ionize van der Waals and hydrogen bonded clusters such that very little energy above the vertical ionization energy (VIE) of the clusters remains in the cluster. Cluster metastable fragmentation is driven in most instances by the energy difference between cluster VIE and adiabatic ionization energy (AIE) or the energy difference between VIE and the barrier to the proton transfer/dissociation reaction following ionization [e.g., $\quad\left(\mathrm{H}_{2} \mathrm{O}\right)_{2} \rightarrow\left(\mathrm{H}_{2} \mathrm{O}\right)_{2}^{+}+e^{-}$ $\left.\rightarrow\left(\mathrm{H}_{2} \mathrm{O}\right) \mathrm{H}^{+}+\mathrm{OH}^{+}+e^{-}\right]$.

Carbon dioxide clusters are van der Waals in nature with a $\left(\mathrm{CO}_{2}\right)_{2}$ pair bonding energy of ca. $1.3 \mathrm{kcal} / \mathrm{mol}$ (Ref. 28) compared to $\left(\mathrm{H}_{2} \mathrm{O}\right)_{2}$ pair bonding energy of ca. $5 \mathrm{kcal} / \mathrm{mol}^{29}$ As illustrated in Fig. 1, signals for $\left(\mathrm{CO}_{2}\right)_{n}^{+}$ cluster ions dominate the spectrum for all $n$. Signals for $\left(\mathrm{CO}_{2}\right)_{n-1} \mathrm{CO}^{+}$and $\left(\mathrm{CO}_{2}\right)_{n-2} \mathrm{O}_{2}^{+}$become increasingly weak in the range $n=1-4$. These results are in stark contrast with electron impact results ${ }^{16}$ for $\left(\mathrm{CO}_{2}\right)_{n}$ clusters, in which such fragmentation yields nearly $50 \%$ of the cluster ion intensity for $n=5,16$. For $26.5 \mathrm{eV}$ single photon ionization the summed relative intensities for fragment ions have a ratio $<0.01$ for all values of $n$. These results, in conjunction with 
linear TOFMS data, strongly suggest that the neutral cluster $\left(\mathrm{CO}_{2}\right)_{n}$ distribution is quite similar to the observed $\left(\mathrm{CO}_{2}\right)_{n}^{+}$ distribution.

Metastable fragmentation (outside the ionization/ extraction region of the TOFMS, $t>1 \mu \mathrm{s}$ ) occurs with nearly the same rate constant for all van der Waals and hydrogen bonded cluster ions studied with $26.5 \mathrm{eV}$ single photon photoionization. ${ }^{25,26}$ This coincidence implies a loose relation between cluster binding energy, (VIE-AIE), $\Delta \mathrm{H}$ for proton transfer and binding energy for $\mathrm{OH}$ and $\mathrm{NH}_{2}$ in their respective clusters, and the barriers to proton transfer reactions in the appropriate clusters. While this is far from a quantitative relationship, such a connection is qualitatively implied by the similar rate constants. What is implied by these metastable rate constant similarities is that the details of cluster structure and limiting potential energy models are less important than the overall cluster density of states and statistical or ergodic behavior. Since the metastable dissociation rate constants increase with increasing cluster size (see Fig. 9), the cluster vibrational temperature must increase with cluster size as well.

Based on our results, we consider that most neutral carbon dioxide clusters $\left(\mathrm{CO}_{2}\right)_{n}$ are free of fragmentation directly following the single photon ionization of the soft $\mathrm{x}$-ray laser. This claim can be supported by three main observations. First, the peaks observed in the mass spectra are sharp and symmetrical, implying that cluster fragmentation does not occur in the first $<1 \mu$ s following ionization. Second, the loss of only one carbon dioxide molecule is observed in the field-free region after ionization. The metastable rate constants of the carbon dioxide cluster ions are similar to water, ammonia, and methanol. ${ }^{25}$ Reference 25 presents many arguments that support almost no fragmentation for van der Waals clusters. Similar rate constants indicate similar behavior of the clusters following ionization. Third, we observe unprotonated mixed water-carbon dioxide clusters. This shows that during ionization, the amount of energy left in the mixed cluster is too small to drive a proton transfer reaction. This will be discussed in more detail in the following sections.

\section{B. Generation of mixed $\mathrm{CO}_{2}-\mathrm{H}_{2} \mathrm{O}$ clusters}

Binding energies for hydrogen bonded clusters are considerably larger than those for non-hydrogen-bonded van der Waals clusters. Additionally the binding energy for the $\left(\mathrm{H}_{2} \mathrm{O}\right)\left(\mathrm{CO}_{2}\right)$ dimer is $920 \mathrm{~cm}^{-1}$ or $0.114 \mathrm{eV} .^{23}$ At high backing pressure and concentration of $\mathrm{CO}_{2}$, the $\left(\mathrm{CO}_{2}\right)_{n}^{+}$cluster ions are the dominant ones in the mass spectrum (Fig. 3). Based on the comparison of metastable decay ratios of $\left(\mathrm{CO}_{2}\right)_{n}^{+}$clusters generated in both of the pure $\mathrm{CO}_{2}$ and mixed $\mathrm{CO}_{2}-\mathrm{H}_{2} \mathrm{O}$ systems (see Fig. 9), one can conclude that $\left(\mathrm{CO}_{2}\right)_{n}^{+}$ions are produced from neutral $\left(\mathrm{CO}_{2}\right)_{n}$ clusters, and not from mixed $\left(\mathrm{CO}_{2}\right)_{n}\left(\mathrm{H}_{2} \mathrm{O}\right)$ clusters. Mixed clusters $\left(\mathrm{CO}_{2}\right)_{n} \mathrm{H}_{2} \mathrm{O}^{+}$lose one $\mathrm{CO}_{2}$ molecule via metastable dissociation, not one water molecule, to form the daughter ion $\left(\mathrm{CO}_{2}\right)_{n-1} \mathrm{H}_{2} \mathrm{O}^{+}$. This latter mechanism is supported by the daughter/parent flight time difference discussed earlier in the last section. The signal intensity of the mixed cluster in
$\left(\mathrm{CO}_{2}\right)_{n} \mathrm{H}_{2} \mathrm{O}^{+}$is about $10 \%$ (for $n=1-5$ ) of that for $\left(\mathrm{CO}_{2}\right)_{n}^{+}$, indicating that $\left(\mathrm{CO}_{2}\right)_{n}$ is a reasonable solvent for $\mathrm{H}_{2} \mathrm{O}$.

We can understand the greater concentration of $\left(\mathrm{CO}_{2}\right)_{n} \mathrm{H}_{2} \mathrm{O}^{+}$unprotonated cluster ions with respect to $\left(\mathrm{CO}_{2}\right)_{n} \mathrm{H}^{+}$or $\left(\mathrm{CO}_{2}\right)_{n}\left(\mathrm{H}_{2} \mathrm{O}\right) \mathrm{H}^{+}$protonated ions in the mass spectrum based on a consideration of the proton affinity of $\mathrm{CO}_{2}(5.61 \mathrm{eV})$ and $\mathrm{OH}(5.74 \mathrm{eV})$. In a hydrogen bonded cluster such as water, the proton affinity of clusters increases with increasing cluster size, so the corresponding energy required for proton transfer initiation becomes small. The protonated $\left(\mathrm{H}_{2} \mathrm{O}\right)_{n} \mathrm{H}^{+}$cluster ion series is always dominant in a water expansion, even for "threshold" (VIE) ionization conditions. ${ }^{25}$ Under the present conditions, almost all of the excess energy above the VIE is removed by the ejected photoelectron in the mixed $\left(\mathrm{CO}_{2}\right)_{n}\left(\mathrm{H}_{2} \mathrm{O}\right)$ cluster series leaving less energy in the nascent cluster ion than required to drive a proton transfer reaction, especially in a non-hydrogenbonded system. $\mathrm{CO}_{2}$ is most likely the initially ionized moiety in the mixed cluster due to larger ionization cross section at $26.5 \mathrm{eV}\left(21 \times 10^{-18}\right.$ vs $\left.14 \times 10^{-18} \mathrm{~cm}^{2}\right)$ (Ref. 30) even though its adiabatic ionization energy is larger than that of $\mathrm{H}_{2} \mathrm{O}$ (13.8 vs $\left.12.6 \mathrm{eV}\right)$.

Under the conditions of low backing pressure and concentration of $\mathrm{CO}_{2}$, condition 2 above, protonated water cluster ions $\left(\mathrm{H}_{2} \mathrm{O}\right)_{n} \mathrm{H}^{+}$dominate the mass spectrum, while the $\left(\mathrm{CO}_{2}\right)_{n}^{+}$cluster ion series is detected only for $2 \leqslant n \leqslant 7$. This latter series is generated from $\left(\mathrm{CO}_{2}\right)_{n}$ neutrals (Fig. 6). This is documented by the metastable rate constants for $\left(\mathrm{CO}_{2}\right)_{n}$ with and without water present in the system. From Fig. 9 one notes that the rate constants for both conditions are very similar, suggesting that the $\left(\mathrm{CO}_{2}\right)_{n}^{+}$series of cluster ions is generated by the same process, with and without water in the expansion, from neutral $\left(\mathrm{CO}_{2}\right)_{n}$ clusters. Additionally, for this set of experimental parameters no $\left(\mathrm{CO}_{2}\right)_{n} \mathrm{H}_{2} \mathrm{O}\left(\mathrm{H}_{2} \mathrm{O}\right)_{m}(n>2)$ clusters are detected.

The distribution of $\left(\mathrm{H}_{2} \mathrm{O}\right)_{n} \mathrm{H}^{+}$ions generated under these low pressure, low concentration conditions for $\mathrm{CO}_{2}$ is the same as that generated in a pure water/He expansion. For the mixed $\mathrm{H}_{2} \mathrm{O}-\mathrm{CO}_{2}$ system, two possible channels can be identified for the generation of protonated water cluster ions,

$$
\left(\mathrm{H}_{2} \mathrm{O}\right)_{n}+h \nu \rightarrow\left\{\left(\mathrm{H}_{2} \mathrm{O}\right)_{n}^{+}\right\}^{*}+e^{-} \rightarrow\left(\mathrm{H}_{2} \mathrm{O}\right)_{n-1} \mathrm{H}^{+}+\mathrm{OH}+e^{-}
$$

and

$$
\begin{aligned}
\left(\mathrm{CO}_{2}\right)_{m}\left(\mathrm{H}_{2} \mathrm{O}\right)_{n}+h \nu & \rightarrow\left\{\left(\mathrm{CO}_{2}\right)_{m}\left(\mathrm{H}_{2} \mathrm{O}\right)_{n}^{+}\right\}^{*}+e^{-} \\
& \rightarrow\left(\mathrm{H}_{2} \mathrm{O}\right)_{n-1} \mathrm{H}^{+}+\mathrm{OH}+e^{-}+m \mathrm{CO}_{2}
\end{aligned}
$$

Assuming reaction (9) occurs, one could also assume that most of the excess photon energy produced by the laser would be absorbed by the ejected $m \mathrm{CO}_{2}$ molecules, causing a decrease in the metastable dissociate rate of the protonated cluster ions $\left(\mathrm{H}_{2} \mathrm{O}\right)_{n} \mathrm{H}^{+}$(e.g., losing one additional $\mathrm{H}_{2} \mathrm{O}$ molecule). The protonated water cluster parent/daughter signal intensity ratio is similar to the pure water system previously studied, in that the parent and daughter signal intensities switch dominance at the same value of $n(\sim 14 / 15)$ in both experiments. This indicates that the protonated water cluster 
ions do not form by the mixed cluster ion series $\left(\mathrm{CO}_{2}\right)_{m}\left(\mathrm{H}_{2} \mathrm{O}\right)_{n} \mathrm{H}^{+}$losing the appropriate amount of $\mathrm{CO}_{2}$, but from the neutral $\left(\mathrm{H}_{2} \mathrm{O}\right)_{n}$ clusters through a proton transfer reaction.

Nonetheless, evaporation of $m \mathrm{CO}_{2}$ molecules from a mixed cluster does effect the (weak) appearance of $\left(\mathrm{CO}_{2}\right)$ $\times\left(\mathrm{H}_{2} \mathrm{O}\right)_{n}^{+}$and $\left(\mathrm{H}_{2} \mathrm{O}\right)^{+}$via reactions (5) and (6), as shown in Fig. 7. Thus for these minor components of the mass spectra of mixed $\mathrm{CO}_{2}-\mathrm{H}_{2} \mathrm{O}$ clusters, the $\mathrm{CO}_{2}$ molecule behaves in a similar fashion to Ar with respect to removing excess energy (in this instance above the AIE) from the cluster through evaporation of the more weakly bound species. ${ }^{31}$ Note that $\left(\mathrm{CO}_{2}\right)_{2}\left(\mathrm{H}_{2} \mathrm{O}\right)_{1} \mathrm{H}^{+}$and $\left(\mathrm{CO}_{2}\right)_{2}\left(\mathrm{H}_{2} \mathrm{O}\right)_{2} \mathrm{H}^{+}$clusters are very weakly observed in the spectrum of Fig. 7.

\section{CONCLUSIONS}

Pure neutral $\left(\mathrm{CO}_{2}\right)_{n}$ clusters and $\left(\mathrm{CO}_{2}\right)_{n}\left(\mathrm{H}_{2} \mathrm{O}\right)_{m}$ mixed clusters are investigated by TOFMS employing single photon of $26.5 \mathrm{eV}$ ionization. For the pure $\mathrm{CO}_{2}$ system, the dominant cluster series in the mass spectrum is $\left(\mathrm{CO}_{2}\right)_{n}^{+}$which is directly generated from ionization of neutral clusters $\left(\mathrm{CO}_{2}\right)_{n}$ in the molecular beam. The distribution of $\left(\mathrm{CO}_{2}\right)_{n}$ neutral clusters decreases roughly exponentially with increasing cluster size $n$ showing no anomalous signal intensities in the distribution. The $\left(\mathrm{CO}_{2}\right)_{n-1} \mathrm{CO}^{+}$and $\left(\mathrm{CO}_{2}\right)_{n-2} \mathrm{O}_{2}^{+}$cluster series are observed (weakly) as the photodissociation products of the neutral $\left(\mathrm{CO}_{2}\right)_{n}$ clusters at a highly excited state of the ion. Compared to electron impact studies, much less dissociation is observed because in most instances all of the excess cluster energy above VIE is removed by the photoelectron during the ionization process.

For the van der Waals cluster $\left(\mathrm{CO}_{2}\right)_{n}^{+}$, metastable dissociation by loss of only one $\mathrm{CO}_{2}$ molecule from the cluster is observed in the reflectron TOF mass spectrum for $26.5 \mathrm{eV}$ single photon ionization. The metastable dissociation rate constants for $\left(\mathrm{CO}_{2}\right)_{n}^{+}$loss of $\mathrm{CO}_{2}$ are in the range of $(0.2-1.5) \times 10^{4} \mathrm{~s}^{-1}$ for $5 \leqslant n \leqslant 16$. This is the same range observed for the comparable dissociation of $\left(\mathrm{SO}_{2}\right)_{n}^{+}$, $\left(\mathrm{H}_{2} \mathrm{O}\right)_{n} \mathrm{H}^{+},\left(\mathrm{CH}_{3} \mathrm{OH}\right)_{n} \mathrm{H}^{+}$, and $\left(\mathrm{NH}_{3}\right)_{n} \mathrm{H}^{+}$clusters. These rate constants imply that cluster dynamics is dependent upon cluster density of states and internal cluster temperature.

Mixed $\mathrm{CO}_{2}-\mathrm{H}_{2} \mathrm{O}$ clusters are studied at two different conditions of $\mathrm{CO}_{2}$ concentration in the expansion gas and two different expansion gas pressures. The predominant signals in the mass spectra are $\left(\mathrm{CO}_{2}\right)_{n}^{+}$and $\left(\mathrm{H}_{2} \mathrm{O}\right)_{n} \mathrm{H}^{+}$cluster ions for high and low parameter values, respectively. Both cluster ion series arise from pure neutral and not mixed clusters. For the high concentration condition two more cluster series, $\left(\mathrm{CO}_{2}\right)_{n} \mathrm{H}_{2} \mathrm{O}^{+}$and $\left(\mathrm{CO}_{2}\right)_{n}\left(\mathrm{H}_{2} \mathrm{O}\right)_{2}^{+}$are observed. The $\mathrm{x}$-ray laser photon does not deposit enough energy in the $\left(\mathrm{CO}_{2}\right)_{n}\left(\mathrm{H}_{2} \mathrm{O}\right)_{1,2}^{+}$clusters to cause proton transfer to $\mathrm{CO}_{2}$ or $\mathrm{H}_{2} \mathrm{O} . \mathrm{CO}_{2}$ acts as a good solvent for $\mathrm{H}_{2} \mathrm{O}$ molecules. At low concentration and backing pressure, many additional cluster ion series are observed. The unprotonated $\left(\mathrm{H}_{2} \mathrm{O}\right)_{n}^{+}$and $\left(\mathrm{CO}_{2}\right)_{m}\left(\mathrm{H}_{2} \mathrm{O}\right)_{n}^{+}$series are generated by the evaporation of $\mathrm{CO}_{2}$ molecules from the mixed cluster series $\left(\mathrm{CO}_{2}\right)_{m}\left(\mathrm{H}_{2} \mathrm{O}\right)_{n}^{+}$.
In general, the behavior of $\left(\mathrm{CO}_{2}\right)_{n}$ and $\left(\mathrm{CO}_{2}\right)_{n}^{+}$clusters parallels that found for other van der Waals and hydrogen bonded clusters with regard to cluster distribution, cluster dissociation, and cluster vibrational temperature.

\section{ACKNOWLEDGMENT}

This research has been supported in part by the NSF ERC for Extreme Ultraviolet Science and Technology under NSF Award No. 0310717. Other support from this work comes from the U.S. DOE, NSF, and Philip Morris U.S.A.

${ }^{1}$ C.-G. Rossby, in The Atmosphere and the Sea in Motion, edited by B. Bolin (Rockefeller Institute Press, New York, 1959), pp. 9-50; Inadvertent Climate Modification, edited by C. L. Wilson and W. H. Matthews (MIT, Cambridge, MA, 1971).

${ }^{2}$ H. Falter, O. F. Hagena, W. Henkes, and H. V. Wedel, Int. J. Mass Spectrom. Ion Phys. 4, 145 (1970).

${ }^{3}$ O. F. Hagena, Entropie 42, 42 (1971).

${ }^{4}$ K. Stephan, J. H. Futrell, K. I. Peterson, A. W. Castleman, Jr., and T. D. Mark, J. Chem. Phys. 77, 2408 (1982).

${ }^{5}$ G. Jones and J. Taylor, J. Chem. Phys. 68, 1768 (1978).

${ }^{6}$ (a) S. H. Linn and C. Y. Ng, J. Chem. Phys. 75, 4921 (1981); (b) L. Wang, J. E. Reutt, Y. T. Lee, and D. A. Shirley, J. Electron Spectrosc. Relat. Phenom. 47, 167 (1988).

${ }^{7}$ G. Torchet, H. Bouchier, J. Farges, M. F. de Feraudy, and B. Raoult, J. Chem. Phys. 81, 2137 (1984).

${ }^{8}$ J. A. Barnes and T. E. Gough, J. Chem. Phys. 86, 6012 (1987).

${ }^{9}$ G. Torchet, M. F. de Feraudy, A. Boutin, and A. H. Fuchs, J. Chem. Phys. 105, 3671 (1996)

${ }^{10}$ G. Cardini, V. Schettino, and M. L. Klein, J. Chem. Phys. 90, 4441 (1989).

${ }^{11}$ A. Bonnamy, R. Georges, A. Benidar, J. Boissoles, A. Canosa, and B. R. Rowe, J. Chem. Phys. 118, 3612 (2003).

${ }^{12}$ M. A. Ovchinnikov and C. A. Wight, J. Chem. Phys. 100, 972 (1994).

${ }^{13}$ T. E. Gough and T. Y. Wang, J. Chem. Phys. 105, 4899 (1996).

${ }^{14}$ J. L. Foster, A. C. Chang, D. K. Hall, W. P. Wergin, E. F. Erbe, and J. Barton, J. Geophys. Res., [Planets] 103, 25839 (1998).

${ }^{15}$ G. Romanowski and K. P. Wanczek, Int. J. Mass Spectrom. Ion Process. 95, 223 (1989)

${ }^{16}$ J. Dabek and L. Michalak, Vacuum 63, 555 (2001).

${ }^{17}$ G. Romanowski and K. P. Wanczek, Int. J. Mass Spectrom. Ion Process. 62, 277 (1984).

${ }^{18}$ G. Romanowski and K. P. Wanczek, Int. J. Mass Spectrom. Ion Process. 70, 247 (1986).

${ }^{19}$ Y. Negishi, T. Nagata, and T. Tsukuda, Chem. Phys. Lett. 364, 127 (2002).

${ }^{20}$ L. W. Sieck and R. Gorden, Jr., J. Res. Natl. Bur. Stand., Sect. A 78A, 315 (1974).

${ }^{21}$ J. H. Futrell, K. Stephan, and T. D. Mark, J. Chem. Phys. 76, 5893 (1982).

${ }^{22}$ P. A. Block, M. D. Marshall, L. G. Petersen, and R. E. Miller, J. Chem. Phys. 96, 7321 (1992).

${ }^{23}$ J. Sadlej, J. Makarewicz, and G. Chalasinski, J. Chem. Phys. 109, 3919 (1998).

${ }^{24}$ A. Khan, J. Mol. Struct. 665, 237 (2003).

${ }^{25}$ F. Dong, S. Heinbuch, J. J. Rocca, and E. R. Bernstein, J. Chem. Phys. 124, 224319 (2006).

${ }^{26}$ F. Dong, S. Heinbuch, J. J. Rocca, and E. R. Bernstein, J. Chem. Phys. 125, 154317 (2006), following paper.

${ }^{27}$ S. Heinbuch, M. Grisham, D. Martz, and J. J. Rocca, Opt. Express 13, 4050 (2005).

${ }^{28}$ A. J. Illies, M. L. McKee, and H. B. Schlegel, J. Phys. Chem. 91, 3489 (1987).

${ }^{29}$ J. T. Su, X. Xu, and W. A. Goddard III, J. Phys. Chem. A 108, 10518 (2004).

${ }^{30}$ N. Wainfan, W. C. Walker, and G. L. Weissler, Phys. Rev. 99, 542 (1955).

${ }^{31}$ H. Shiromaru, N. Nishi, and N. Washida, J. Chem. Phys. 84, 5561 (1986). 